\title{
Election Predictions: Theory and Social Science
}

\author{
Glenn H. Utter, Lamar University \\ James M. Vanderleeuw, Lamar University
}

An important concern for political scientists is the extent to which the discipline has progressed as a science. Political science has based its claim to being a science on its ability to construct models that predict as well as explain political phenomena. We examine the role that philosophers of science have given to prediction in science generally, and then note examples from the history of science that demonstrate a varied role for prediction in differing sciences. A review of the literature on predicting congressional and presidential election outcomes indicates the impressive success of predictive models. Nonetheless, such models are often open to the criticism that they lack a firm theoretical foundation.

As a discipline, the study of politics bases its claim to being a science on criteria that include the process of building on and modifying previous findings, replicability, and the ability, based on testable hypotheses drawn from theory, to explain as well as predict political phenomena. This paper focuses on the latter of these concerns. The central question addressed here--one that has been asked before but necessitates continued discussion--is how political scientists regard the relationship between theoretical models that offer the basis for explanation, and the attempt to fit models to data, specifically in the form of predictions. In order to answer this question we specifically examine models developed to predict election outcomes.

We begin by examining the role philosophers of science have given prediction in the enterprise of science generally, contrasting the "reconstructed logic" of prediction with its "logic in use" as observed in examples from the history of science. We then review the research concerned with predicting election outcomes, examining the accuracy of predictive models in order to shed light on the role political scientists grant to prediction in the development and testing of theory.

\section{Prediction and Science}

The "Reconstructed Logic" of Prediction

The importance of prediction in science has at least two legitimating sources. First, Popper $(1968,39)$, wanting to distinguish between empirical statements of the sciences and other statements char- 
acteristic of religion, metaphysics, or the pseudo-scientific, emphasizes the criterion that scientific theories be testable in specific ways. For instance, he would put Marxism in the category of pseudo-science, denying it the status of a scientific theory because it lacks clear criteria for testing. In order to make this distinction, Popper establishes the criterion of falsifiability: statements must be capable of disagreeing with observations in order to be classified as scientific. Therefore, Popper's conception of scientific procedure involves constant attempts to falsify proposed theories. Falsification constitutes the basic element in science, distinguishing science from pseudo-science.

Tests to which a theory should be subjected include internal consistency, logical form, and comparison with alternative theories to determine if the new theory would represent a scientific advance (Popper 1959, 32-33). Ultimately, however, a scientific theory must be subjected to empirical tests of any deductions from the theory. Such deductions are especially valuable for testing if they differ from those that would be deduced from an alternative theory. If a theoretically derived prediction proves correct, the theory has at least temporarily passed the test and avoided refutation. If not, the theory itself is refuted. A theory's truth can never be demonstrated unconditionally, but rather establishes its status through withstanding successive attempts at falsification.

Prediction also holds an important place in the deductive-nomological model of explanation and its variants (Hempel 1965) that posit a logical identity between explanation and prediction: if a theory can explain, it can predict, and if it can predict, it can explain. When someone claims to have successfully explained a phenomenon, a reasonable question is: If you have a good explanation, then what would you expect to happen if relevant conditions should change in certain ways? Isaak $(1975,142)$ emphasizes the logical identity of explanation and prediction: "If, given the proper initial conditions, one could not have predicted the event that was explained, the explanation was not adequate in the first place."

\section{The "Logic in Use" of Prediction}

Actual scientific practice does not indicate a clear-cut relationship between explanation and prediction. For instance, Pinch (1985) questions the applicability of Popper's criterion of falsifiability to ongoing scientific investigation. Scientists must make decisions as to 
when a theory has actually been falsified, and scientists may disagree. The logic of falsification itself cannot resolve differing interpretations. Mulkay and Gilbert (1981) come to the same conclusion that the relationship between rules of falsification and their application is fundamentally indeterminate.

The deductive-nomological model for scientific explanation has also been questioned. Critics of the identity of explanation and prediction assert, contrary to the model, that explanation and prediction may be separable (see, e.g. Kaplan 1964; Diesing 1971). Darwin's theory of the origin of species, for example, can be accepted as offering an adequate explanation for the development of species without necessarily being able to predict the next evolutionary stage: the theory has a capacity for retrodiction, but not prediction. Conversely, Kaplan observes that prediction may be no more than the result of empirical generalization: while a prediction may be successful, it may represent nothing like an adequate explanation. As Gjertsen $(1989,109)$ observes, "a false hypothesis can lead to surprising and true predictions just as readily as a true hypothesis."

The further we move from the reconstructed logic of science interpreted as a prescription for what scientists ought to do, and the closer we come to the history of science and accounts of what scientists actually do, the more tenuous can be the relationship between scientific explanation and prediction. The place of predictions and the data to test them tends to vary with specific scientific disciplines. Scientific theories that failed to be good predictors or did not generate readily testable predictions nonetheless can be widely accepted by members of a scientific community. A theory may be persuasive for reasons other than its ability to make testable predictions, such as for its "beauty" and "elegance" (Kuhn 1972, 72).

The history of science offers varied accounts of the association between explanation and prediction. The examples that Nie (1989) presents in his discussion of "model" vs. "data driven" science tend to support the view that a close relationship exists between explanation and prediction. New models overturn older ones because they better fit the constantly accumulating data. Nie presents examples from ongoing research in the natural and social sciences that involve findings which have led, or promise to lead, to paradigm shifts. Such an argument should not be taken for pure empiricism: for there to be a paradigm shift, there must already be a paradigm guiding research. One criterion of a more successful paradigm is that it provides for more 
accurate prediction, or makes predictions that its opponent cannot make. Additionally, although models advance to the extent they become better approximations of "reality," they are not identical to what they attempt to describe. To hold such a position involves what Rudner $(1966,69)$ terms the "reproductive fallacy:" the claim that scientific models, to be deemed successful, should recreate a part of the world. Although we do not believe Nie commits this fallacy, we would expect that the relationship between explanation and prediction, and hence between model and data, varies from discipline to discipline more than Nie suggests.

Other examples in the history of science suggest a more remote relationship between a scientific explanation and data-based predictions. Just as scientists might commit themselves to a theory independently of testing predictions, it may require more than the accuracy or inaccuracy of a prediction to draw scientists away from an accepted theory. Early attempts to test Einstein's general theory of relativity illustrate the tenuous link between a theory and attempts at falsification. Einstein's theory makes a precise prediction, as a consequence of the curvature of space, for the deflection of light as it passes near the sun that amounts to twice the value that Newton's theory of gravity predicts (Will 1986, 74-79). In 1919, two expeditions made observations during a solar eclipse in order to test these conflicting predictions. Although the results were less than conclusive, they were taken as an important support for Einstein's theory. Among scientists, the general theory of relativity remained the accepted perspective for nearly forty years without major efforts at retesting. ${ }^{1}$

Another example of the uncertain relationship between explanation and prediction comes from geology. The theory of plate tectonics claims that the ocean beds are in a constant state of reformation because the earth's crust is composed of several "plates" in continuous motion. Originally ridiculed, the theory has in recent years gained widespread acceptance; but the relationship between the new model and data is not unambiguous. As Frankel $(1978,208)$ notes, both proponents ("mobilists") and opponents ("fixists") of the new model provided different interpretations of the same information. The empirical evidence did not speak for itself, for geologists on both sides questioned the reliability and relevance of data. Associated with this phenomenon is what Kitts $(1978,218))$ has referred to as "predictive uncertainty" in geology. Geological events occur primarily in the past and therefore in evaluating data, geologists rely almost exclusively 
upon retrodiction rather than prediction. Hence conflicting interpretations have rivaled the data itself in importance for theory development.

An alternative theory, despite successful predictions, may not be accepted by fellow scientists. Swedish Astronomer Hannes Alfven, for example, suggested an alternative explanation for the formation of the solar system: the early sun's magnetic field ionized clouds of gases that ultimately formed the planets (Brush 1981, 90-91). Even though Alfven's theory made successful predictions-- for instance, that there are rings around the planet Uranus--astronomers rejected much of his explanation for the solar sytems's origin: his explanation failed to fit the existing understandings of the community of astronomers. Successful prediction, therefore, need not be the crucial factor in giving a theory credibility.

These examples from the history of science suggest that the basis for accepting a scientific model varies from discipline to discipline and depends upon the unique circumstances and subject matter of a science. Although data and resulting predictions can play a crucial role in theory development, theory independent of test results may be judged both in terms of its elegance and its consistency with what the scientific community has already accepted.

\section{Prediction and Elections}

\section{Quasi-Scientific Approaches}

Predictions in political science face added complications because the very notion of theory testing is problematic. For instance, the predictive success of Duverger's law has not been taken as an unequivocal example of scientific explanation. Duverger's law holds that single member district plurality voting procedures will result in twoparty systems. ${ }^{2}$ In his critique of Duverger's law, MacIntyre $(1971,268)$ points to the tenuous relationship between theory and prediction in political science. Although representing an accurate prediction, MacIntyre regards this claim to be eminently untheoretical, representing an assertion of general human rationality. Therefore, testing Duverger's law amounts to restating the claim that human beings are rational in making choices.

Given MacIntyre's criticism, is anything like a theory of elections being tested by empirical models claiming to predict election 
outcomes? Rather than deductions from a theory, prediction might rely on either generalized truisms about behavior or involve a kind of ad hoc model building with variables chosen not because they play an important role in testing a proposed theory, but because statistical analysis reveals a correlation between certain variables and voting behavior. In essence, predictive models may state in more efficient terms what has already been expressed in other ways.

The model developed by Lichtman (Lichtman and KeilisBorok 1981), while methodologically sophisticated, clearly indicates the "common-sense" nature of the reasoning involved in many election prediction models. He employs a set of thirteen dummy variables--for instance, whether or not the incumbent party has been in office more than one term, whether there is a major third party movement during the election year, whether the election year is a time of recession or depression, whether the incumbent party candidate is "charismatic" or a "national hero"-- to predict presidential election outcomes from 1860 to the present. He predicted a Republican victory in 1988 as early as May (Weaver and Toner 1988). The "theory" underlying such a model involves an argument about how each (more or less impressionistically) chosen variable might be expected to "explain" part of the vote outcome. The variables chosen are fairly widely recognized as potentially important factors in determining the election outcome because each reflects likely considerations present in individual vote choices.

The development of the Minnesota Multiphasic Personality Inventory (MMPI), a test employed in psychiatry and psychology, closely resembles the situation suggested for election predictions. The original purpose of the MMPI was to help differentiate between normal and abnormal categories of individuals. Hathaway and McKinley, originators of the MMPI, developed the inventory through procedures not closely related to scientific theory. They derived items from various sources, including case histories, psychological reports, and psychiatry textbooks, in addition to previous personal and social attitude scales (Hathaway and McKinley 1956). Concurrent validity was achieved by relating testing results to traditional psychological examination, and construct validity has developed over time with the gradual accumulation of research data that reveal typical patterns of scores (Anastasi 1988, 531). Although the MMPI has been criticized--for instance, for inadequate test reliability--it has continued to be used and modified from its original form (Friedman, Webb, and Lewak 1989). Theory testing through prediction does not appear to characterize the 
procedure behind the MMPI, but rather involves the steady accumulation of empirical data.

Do models of election forecasts differ from this type of empirical approach, one devoid of any explicit theoretical grounding? At a minimum, political scientists would likely admit that the models they develop are generally superior to those quasi-scientific forecasts often reported by the popular press. Lewis-Beck (1985), for instance, offers examples of prediction that are successful for some elections, but which he labels lucky guesses--an American League victory in the World Series indicates a Republican victory; a bad Beaujolais wine harvest forecasts a Republican victory; a higher Dow Jones average on the Monday before the election leads to an incumbent victory; the taller presidential candidate will win. Each could be fitted with a possible rationale. The last, for example, might involve the claim that voters prefer taller and therefore more authoritative-appearing individuals as their presidents, a prediction that failed in 1976. Generally, predictions of this sort, while often entertaining and at times successful in picking the winning candidate, lack surface plausibility due to the absence of a sufficiently persuasive connection to electoral politics.

Other forecasts reported by the press do appear to involve a closer connection among the phenomena under investigation. Zullow (Gelman 1988), a psychologist, developed a model based upon an evaluation of the optimistic versus pessimistic content of presidential candidates' speeches. Prior to the 1988 election, he reported correctly picking the winner in nine out of ten of the last presidential elections. However, he failed to predict a Bush victory in $1988 .{ }^{3}$ Another prediction is based on selecting as the winner the candidate with the longest name. Schaeffer (1984) pointed out the success of this approach in 27 of 34 applicable elections prior to 1984 (a $79 \%$ accuracy rate). The model, however, failed to predict both the 1984 and 1988 elections.

A further approach involves examining rainfall (Marshall 1988). From 1825 to 1924 , the amount of rainfall in specified regions of the country in the four years preceding the election indicated the victorious candidate. Above average rainfall forecast an incumbent party victory, while below average rainfall presaged a change of party. From 1825 to 1884 , Marshall noted that precipitation in the northeastern states correctly predicted the winner in 13 out of 15 elections. From 1885 to 1924 precipitation in the west north central states successfully indicated the winner in 9 out of 10 elections. An apparent reason for 
the model's success is the earlier agricultural orientation of the nation. Bad harvests translated into political discontent aimed at the incumbent presidential party. Marshall, writing in 1924, reached conclusions that are, as we shall see, similar to those made in reaction to more recent predictive models: "[H] istorians have so emphasized the petty actions of puny politicians that it seems worth while stressing one factor which even the largest campaign fund cannot alter" (Marshall 1988, 263).

\section{Predictive Models in Political Science}

While these types of predictions may on occasion be successful, they can hardly lay claim to being in any way theoretical or derived from a theoretical framework. The empirical models employed by political scientists studying election outcomes differ from these approaches by, first, utilizing variables presumed to be linked more directly to voting behavior. In addition, rather than making a winner-loser prediction, they can produce fairly precise predictions by forecasting the percentage of the vote for one of the two major parties. Finally, the models of behavior developed by political scientists are intended to reflect some theoretical concern.

Up to the 1960 s, predicting election outcomes was fairly closely associated with the political arena, being journalistically inspired or having practical uses for candidates. The failures of early attempts at predicting presidential election outcomes--for example the legendary 1936 Literary Digest poll's failure to predict a Roosevelt victory, and the failure of major polling organizations to predict the 1948 Truman victory--pointed out the need to develop more thoroughly scientific techniques. Although voting studies within political science had been concerned for some time with explaining Americans' voting behavior, it was not until the 1970's that a series of studies were published having the explicit objective of predicting election outcomes.

Tufte (1975) as well as Kernell (1977) developed a model of voting in mid-term congressional elections that challenged what was up until that time the traditional model of mid-term election outcomes. The traditional model posited that in the absence of short-term events related to the high visibility presidential election, the electorate reverted to a more "natural" voting pattern in the mid-term election, resulting in a loss of seats for congressional members of the president's party. However, citing evidence that the partisan composition of the 
voters in mid-term elections (percentage Democrats, Republicans and Independents) tended to be the same as that in presidential election years, Kernell (1977) argued that the traditional model was seriously flawed. The traditional model was premised on the notion that the partisan composition of the voters in mid-term elections was substantially different from that in presidential election years (the presidential election was presumed to mobilize a larger share of independents). The traditional model, therefore, fell short on two counts: it failed to predict the partisan composition of the electorate in mid-term congressional elections, and the empirical findings on this point could not explain the phenomenon in question--loss of seats for members of the president's party in off-year elections--within the model's theoretical framework.

Both Tufte (1975) and Kernell (1977) proposed an alternate explanatory theory, positing that mid-term congressional elections were essentially referenda on presidential performance. Although the person elected president comes into office with a reservoir of good will and a period of good relations with Congress, two years into his term the discrepancy between campaign pledges and actual performance can bring the public to evaluate the president quite differently. The congressional mid-term election provides the first opportunity for voters to register their satisfaction/dissatisfaction with the president's performance. According to Kernell, dissatisfied voters who wish to punish representatives of the president's party are the most likely to cast a ballot.

Based on this theoretical construct (the referendum model), both Tufte and Kernell hypothesized that the electorate's behavior will be associated closely with presidential popularity and with economic conditions. Here, the works of Tufte and Kernell provide examples of political science research that strive both to explain and predict, deriving hypotheses and measures of behavior from a clearly developed theoretical premise.

Although this simple referendum model of mid-term elections offers a plausible as well as testable explanation of the electorate's behavior and, ultimately, election outcomes, Jacobson and Kernell (1982) argued that the model may in fact predict badly for any given offyear election. That is, the model may overestimate the losses to congressional members of the president's party. Jacobson and Kernell proposed a modification that would take into account candidates' decisions to run for office and, therefore, the choice of candidates 


\section{Glenn H. Utter and James M. Vanderleeuw}

offered to voters. For example, if strong candidates of the president's party were encouraged and persuaded to seek office, regardless of economic conditions, members of the president's party may wind up with a larger share of the vote than if these candidates decided to sit out the election. Voter behavior in this view, then, can be explained as a function of the quality of the candidates with which the electorate is presented. While plausible as an explanation of why some mid-term congressional elections, such as the 1982 election, may not be as harmful to members of the president's party as predicted by the referendum model, Jacobson and Kernell leave it to others to develop measures necessary to test their thesis: a thesis with a certain allure and explanatory plausibility, but one that without proper empirical measures cannot be validated. ${ }^{4}$

The use of presidential popularity as a component of modeling voting behavior in mid-term congressional elections contributes to the discipline's claim to be a science in two ways. First, this measure was derived logically from an initial theoretical foundation, and thus has explanatory appeal. Second, it is meaningful, if not in all cases totally successful, as a predictor because voting in mid-term elections and presidential popularity are separable, referring to two distinct political actors. On at least the second count, however, the models used to address presidential election outcomes are inadequate.

Sigelman (1979) constructed a model examining the impact of presidential popularity (measured by Gallup's final preelection poll) on popular vote for the incumbent that accounted for about $54 \%$ of the variation in the popular vote, 1940 to 1976 . Given the poor performance of Sigelman's model in the 1980 election, however, Lewis-Beck and Rice (1982) modified this model by using the June poll--close to the election but still reflecting a period of "relative political calm" not seriously affected by election histrionics--which accounted for approximately $85 \%$ of the variation in the popular vote, 1948 to 1980 .

In a further modification of this basic model, Brody and Sigelman (1983) changed the dependent variable from votes for the incumbent president to votes for the candidate of the incumbent party, based on evidence of a presidential incumbent "carryover effect" in midterm congressional elections (which accounted for about $67 \%$ of the variation, 1940-1980). Lewis-Beck and Rice (1984) then introduced an additional independent variable-- the growth rate in real per capita GNP in the quarter nine to six months before the election--creating a multivariate model that explained $82 \%$ of the variation in the popular 
presidential vote (they also utilized the May Gallup poll measure of presidential popularity).

Abramowitz (1988) further elaborated on this model by considering the length of time the incumbent party controlled the White House: for one, or more than one term. He assumed that the candidate of the incumbent party is disadvantaged if the party stays in power for at least two terms. In essence, a presidential election is a referendum on the incumbent president (measured by the approval rating in the last Gallup poll before the election) and on the economy (measured by the percentage change in GNP from the last quarter of the previous year to the last quarter of the election year), and reflects the public's mood for change (measured by whether the incumbent party has held the White House for one term or more). This model accounted for $98 \%$ (adjusted $\mathrm{R}^{2}$ ) of the variation for elections from 1948 to 1984 .

Despite the impressive explanatory ability evidenced by these models, in a larger sense, as theoretical explanations, they seem oddly vacuous. If conceptualized as a referendum on job performance, at least on the surface it seems reasonable to use opinion poll results as a measure with which to predict, and therefore validate this model of presidential election outcomes. However, the use of results from polls so near to the general election may leave us with little more than a tautological statement: voters prefer to cast a ballot for the candidate they prefer. In the referendum model of mid-term congressional elections, as stated, presidential job performance and the vote are separable, each referring to a distinctly different actor. In the case of predicting presidential election outcomes, however, these variables are not clearly separate. It seems disingenuous to predict presidential election outcomes based on a measure which in fact may not be sufficiently independent of the behavior in question. As presently operationalized these explanatory models of presidential election outcomes, derived from research on congressional off-year elections, are inappropriate to their subject matter.

We do not take issue with the notion that presidential elections as well as mid-term elections for Congress can be interpreted as referenda on presidential job performance. Rather, we note that presidential election outcomes may not be as independent of presidential job performance as are congressional election outcomes. Congressional candidates, including members of the president's party, can campaign in various ways so as to associate themselves more or less closely 
with the president and his policies, or distance themselves from the president, or even oppose the president's policies. In this sense and context, presidential job performance and presidential election outcome are not comparably independent of one another. Consequently, when attempting to predict presidential election outcomes, it may be preferable to utilize opinion on policy and economic conditions instead of a presidential approval measure.

Perhaps the most famous attempt to predict election outcomes is Rosenstone's (1983) effort. The number of independent variables employed by Rosenstone--thirteen--sets his model apart from those of others involved in the same pursuit. With the Democratic party proportion of the presidential vote as the dependent variable, the independent variables are measures dealing with traditional party vote, issues (New Deal social welfare and racial equality), management of the economy, foreign conflict, incumbency, home-state and regional advantages, and short-term changes in the political environment.

In a review essay, Rice (1985) examined various recent models predicting presidential elections (those of Budge and Farlie 1983; Rosenstone 1983; and Kelley 1983). He asked these researchers to forecast the upcoming 1984 presidential contest based on their respective models. Rosenstone's model proved to be the most accurate predictor. The actual Democratic share of the popular vote was 39.6\% and Rosenstone's model forecast $41.1 \%$, for an error of +1.5 . The Democratic percentage of the two-party vote was $40.9 \%$, yielding an error of +0.2 .

According to Rice, the success of Rosenstone's model emanates from three sources. First, it is based upon "scientific theories of voting" developed through systematic research, distinguishing it from "non-scientific" predictions based on such things as bellwether districts, stock market performance, or the impressions of party professionals. Second, it employs "reasonably precise and easily quantifiable data” (Rice 1985, 685). Finally, Rosenstone's model uses data analysis techniques appropriate to achieving precise vote estimates. However, Rice also has misgivings, asserting that inadequate consideration is given to possible third-party effects. Further, Rice argues that there is no allowance for either the possible consequences of variations in turnout or for serious but unforeseen issues that might arise during a campaign and significantly alter vote choice (Rice 1985, 686). He also is uneasy about the sacrifice of parsimony in a model as complex as Rosenstone's. 
Still, the predictive accuracy of Rosenstone's model does impress. King $(1985,85)$, for instance, emphasizes the model's ability to forecast the 1984 outcome without taking into account issues that arose during the campaign (such as vice presidential candidate Geraldine Ferraro's family finances). Others, however, express considerably less praise for Rosenstone's analysis. Sigelman $(1985,85)$, for example, regards Rosenstone's approach as nontheoretical, arguing that contrary to the author's claim, "[Rosenstone's] book presents nothing recognizable as a theory. Rosenstone's 'theory of elections' is actually a smattering of ideas drawn from hither and yon". Similarly, Barkan $(1984,5)$ concludes that Rosenstone's model "fits on the margin between a political science exercise and political consultant, or journalistic tool" and that it "barely scratches the surface of the questions raised." Lewis-Beck (1985), troubled by Rosenstone's methodology, finds his explanation of index construction "at times difficult to follow, making replication unlikely," and is bothered by the seemingly arbitrary alterations in the model in order to predict the 1980 election.

The predictive ability of Rosenstone's model, therefore, has not necessarily led to an acceptance of his model as a "theory of presidential voting" within the political science community. Even where praise is forthcoming, recommendations for modifying the model are offered. Criticism clusters around the objection that Rosenstone's analysis seems ad hoc, not theory-driven. Variables employed by Rosenstone may in fact offer possible explanations as to why the electorate behaves as it does, but this has yet to be fully developed. Similarly, the interrelationship between these variables has yet to be considered in any theoretically meaningful way. ${ }^{5}$

\section{Theory, Model Building, and Prediction in Political Science}

In examining the nature of scientific investigation, we emphasized the criteria for science as they have been accepted in varied disciplines, including the natural as well as the social sciences. Separate disciplines tend to evolve their own unique emphases on the relationship between explanation and prediction; and the degree of formalization as well as the relationship between models and empirical data varies from discipline to discipline. The models of election campaigns we have discussed tend to rely more on aggregating data than on providing a structural model that attempts to offer a logical 
framework of empirical reality. Distinctions can be made, however. Tufte (1975) and Kernell (1977) construct models that prove appealing to political scientists because they originate in a particular view of midterm elections that differs from the received opinion: rather than representing a systemic adjustment to partisan equilibrium, midterm elections constitute a referendum on the performance of the president's administration. Tufte and Kernell do not simply offer confirmation of common wisdom, but provide a test of conflicting explanations.

The various models for presidential election predictions, although successful, do not fare as well in terms of explanatory theory. These models appear to operationalize inadequately the notion of elections as a referendum on recent past performance of the incumbent administration. Employing presidential popularity as an independent variable, as in the midterm election model, fails to be as convincing because of its apparent redundance: people vote for the candidate (party) they intend to vote for. Sigelman (1979) appropriately acknowledges the strictly predictive nature of his basic model, not claiming any explanatory capacity for it. Rosenstone, who explicitly states that he has developed a theory of elections, has failed to convince political scientists. If political scientists understand theory as involving explanation as well as prediction, a predictive model must demonstrate an interrelationship of elements that provides a plausible theoretical structure prior to any crucial empirical test.

To summarize, the ad hoc nature of presidential election prediction models leaves them open to two basic criticisms. First, the ability of such models to predict may result essentially from the degree of social structure present in the circumstance: the reasons people vote as they do are more or less readily apparent, remain stable, and usually change slowly. Individually, each of us can often accurately predict how friends will vote, given what we know about them, their concerns, and their hopes for the future. A strictly predictive model represents a means of discovering which of these concerns and hopes are most important to the largest number of voters, with the implicit assumption that what is most important about the electoral context for determining voting behavior does not vary markedly over time.

Second, what passes for theory may be seen, according to MacIntyre's interpretation of Duverger's law, as equivalent to a generalized, common-sense notion regarding human rationality. The models assume that individuals with similar interests view the world in similar ways, and as a result will act in the same way. To the extent that the 
results of public opinion polls taken just prior to the general election are prime ingredients, election prediction models may represent tautological statements.

In order to avoid these criticisms, longer-term phenomena might be incorporated into the developing of models and the testing of predictions of presidential elections (as well as other political activities). For example, experience indicates that events crucial to the outcome of an election often extend over a longer time period than an election campaign. Campaign rhetoric and promises, like advertising to sell an unpopular product, may appear feeble inducements next to the cold, hard facts of three years of economic downturn.

Attempts should be made to develop models extending the time-period between the prediction and the event, forcing consideration of different variables and, further, a rethinking of underlying assumptions and theoretical notions. However, even in this case the prediction still may not have any more credibility than a political pundit's ruminations, given the highly structured nature of the election contest.

If political scientists aim at making counter-intuitive predictions in areas far less structured than a presidential election, they conceivably might approach nearer to theory development and thereby pass a true test of scientific theory in the form of recognition by colleagues. Our examination of research predicting election outcomes indicates that political scientists believe the goal of their discipline to be the construction of explanatory models validated through predictive ability. As it stands, the present state of theory building in political science remains uncertain. Although models whose primary goal is prediction have proven admirably accurate in well-defined areas, members of the discipline have been unwilling to confer upon them the title "theory."

\section{NOTES}

${ }^{1}$ Gjertsen (1989) raises an interesting footnote to the eclipse story. A plan to measure the deflection of light during an eclipse in Russia in 1914 had to be cancelled due to the onset of World War I. Had the experiment been completed, one year before the publication of the theory of relativity, Einstein would no longer have been "predicting" an outcome that had so far been unobserved. Although Einstein's theory would have been just as valid, it very likely would not have received such widespread publicity. Einstein's theory of relativity received backing because of experimental results that coincided with a derived prediction based on an already impressive theory. Nonethe- 


\section{Glenn H. Utter and James M. Vanderleeuw}

less, the major thrust of Will's (1986) discussion is to provide descriptions of recent tests of Einstein's theory, which tend to support Nie's "data-driven" view of science.

${ }^{2}$ Rossiter $(1960,9)$ gives an example of the differential effects of singlemember district and proportional representation systems on elections to the New York City council that might be considered as sure a test of a law as any laboratory experiment.

${ }^{3}$ In mid-October, Zullow predicted a Dukakis victory, given a 3.5 percent optimism advantage. Perhaps Zullow became the victim of a self-defeating prophecy by providing his results to both campaign staffs before the election. Nonetheless, a Bush victory appeared fairly certain well before October.

${ }^{4}$ According to Jacobson and Kernell, financial backing for congressional candidates of the president's party may not be as readily forthcoming when contributors expect these candidates to do poorly in the upcoming election. This acts to reduce the number of well-financed and therefore competitive candidates. Jacobson and Kernell's model is an improvement on Tufte's because it establishes a clearer linkage between evaluation of presidential performance and election outcome. Presumably, campaign contributors are more interested in and knowledgable about political events, and are more aware of the overall political context in which the upcoming congressional election takes place, relative to the general public. The more politically attentive (campaign contributors) make a judgment about the way the public will react to candidates of the president's party, relate this to the likelihood of candidate success, and then decide whether to contribute. The general voting public then makes its decision on the basis of the quality of the candidates with which it is ultimately presented.

Jacobson and Kernell leave it to others to operationalize their model, but of course this is part of the research process. A model that includes an analysis of the relationship between campaign contributions (from individuals and political action committees) to candidates of the president's party and candidate success rate over time may be one way to test their thesis.

${ }^{5}$ We perhaps see in the harsh reaction to Rosenstone certain tendencies exhibited by scientists at other times and in other disciplines. We have noted the bias in favor of the generally accepted theory in other scientific disciplines such as astronomy. Rosenstone's model can also be seen as an outlier in that it does not appear to have developed as readily from the basic bivariate model as does the work of other researchers we have discussed. Finally, the charge that Rosenstone's model was too complex brings to mind Rosenau's (1967) lamentation over Snyder et al.'s (1954) decisionmaking theory, and Kuhn's (1972) observation that the scientific community in general places a certain value on the parsimony or elegance of a theoretical model. The reaction of political scientists in this situation, then, is reminiscent of that of scientists in other fields when confronted with a new way of modeling reality.

\section{REFERENCES}

Abramowitz, Alan I. 1988. An Improved Model for Predicting Presidential Election

Outcomes. PS: Political Science and Politics 21: 843-847.

Anastasi, Anne. 1988. Psychological Testing. New York: Macmillan. 